Pesq. Vet. Bras. 37(12):1453-1459, dezembro 2017 DOI: $10.1590 / \mathrm{S} 0100-736 \mathrm{X} 2017001200015$

\title{
Tutores de cães consideram a dieta caseira como adequada, mas alteram as fórmulas prescritas ${ }^{1}$
}

\author{
Dóris P. Halfen², Patrícia M. Oba³, Caio N. Duarte², João Paulo F. Santos ${ }^{3}$, Thiago Henrique \\ A. Vendramini ${ }^{3}$, Maria Cláudia A. Sucupira ${ }^{2}$, Aulus C. Carciofi ${ }^{4}$ e Márcio Brunetto ${ }^{3 *}$
}

\begin{abstract}
Halfen D.P., Oba P.M., Duarte C.N., Santos J.P.F., Vendramini T.H.A., Sucupira M.C.A., Carciofi A.C. \& Brunetto M. 2017. [Dog owners consider homemade diet as adequate, but change the prescribed formulas.] Tutores de cães consideram a dieta caseira como adequada, mas alteram as fórmulas prescritas. Pesquisa Veterinária Brasileira 37(12):1453-1459. Departamento de Nutrição e Produção Animal, Faculdade de Medicina Veterinária e Zootecnia, Universidade de São Paulo, Av. Duque de Caxias Norte 225, Pirassununga SP 19635 900, Brazil. E-mail: mabrunetto@usp.br

The aim of this study was to evaluate the adhesion and perception of dog owners from the city of São Paulo, Brazil, on the employment of homemade diet for the nutritional management of their pet. The participants were 55 owners that provided homemade diet for their dog. The interviews were conducted by telephone and the questionnaire included points related with the preparation and effectiveness of diets, as well as the handling of animals. It was found that a considerable number of prescriptions $(45.9 \%)$ was associated with patients with hyporexia. Among the owners who reported difficulty in the preparation $(10.9 \%)$, time spent $(33.3 \%)$ was the most problematic topic. When questioned in relation to changes in the prescribed formulas, $60 \%$ admitted that conducted it without recommendation. In the opinion of interviewed owners, the homemade diet did not cause changes in feces (50\%) and coat (62.7\%) of the animals compared to the use of a commercial food and was considered appropriate by the majority (79.0\%). The homemade diets can be widely used, being especially important in dogs with diseases and/or dogs with hyporexia, since they are more easily accepted than the commercial diet; however, not all owners are able for its right use.
\end{abstract}

INDEX TERMS: Dogs, unconventional diets, hyporexia, nutritional management.

RESUMO.- 0 estudo objetivou avaliar a adesão e a percepção dos proprietários de cães, residentes na cidade de São Paulo/SP, quanto ao emprego de dieta caseira no manejo nutricional de seu animal de estimação. Foram entrevistados por contato telefônico 55 proprietários que forneciam dieta caseira no manejo nutricional do seu cão. 0 questionário contemplou perguntas relacionadas ao preparo e efi-

\footnotetext{
${ }^{1}$ Recebido em 5 de julho de 2016.

Aceito para publicação em 12 de setembro de 2016.

${ }^{2}$ Departamento de Clínica Veterinária, Faculdade de Medicina Veterinária e Zootecnia (FMVZ), Universidade de São Paulo (USP), Av. Prof. Orlando Marques de Paiva 87, Cidade Universitária, São Paulo, SP 05508-270, Brasil.

${ }^{3}$ Departamento de Nutrição e Produção Animal, FMVZ-USP. Av. Duque de Caxias Norte, Pirassununga, SP 13635-900, Brasil. "Autor para correspondência: mabrunetto@usp.br

${ }^{4}$ Departamento de Clínica e Cirurgia Veterinária, Faculdade de Ciências Agrárias e Veterinária, Universidade Estadual Paulista (Unesp), Via de Acesso Prof. Paulo Donato Castellane s/n, Jaboticabal, SP 14884-900, Brasil.
}

ciência das dietas, bem como o manejo dos animais. Verificou-se que considerável número (parcela) de prescrições $(45,9 \%)$ esteve associado a pacientes com hiporexia. Dentre os proprietários que relataram dificuldade no preparo $(10,9 \%)$, o tempo dispendido $(33,3 \%)$ foi a maior problemática. Quando questionados em relação às modificações nas fórmulas prescritas, $60 \%$ admitiram que a realizaram sem prévia recomendação. Na opinião dos entrevistados, a dieta caseira não causou alterações nas fezes $(50 \%)$ e na pelagem $(62,7 \%)$ dos animais em comparação ao emprego de um alimento comercial e foi considerada adequada pela maioria $(79,0 \%)$. As dietas caseiras podem ser amplamente utilizadas, mostrando-se especialmente importantes em cães doentes e/ou hiporéticos por apresentarem maior aceite em relação à dieta comercial, no entanto, nem todos os tutores estão aptos a utilizá-la.

TERMOS DE INDEXAÇÃO: Caninos, dietas não convencionais, hiporexia, manejo nutricional. 


\section{INTRODUÇÃO}

A prescrição de dietas caseiras tem se tornado cada vez mais requisitada pelos médicos veterinários, por apresentarem como principal vantagem a maior versatilidade em diversas situações clínicas, com fácil adequação ao perfil nutricional de animais em diferentes fases fisiológicas e estados fisiopatológicos, embora as dietas comerciais ofereçam diversas vantagens como praticidade, segurança, equilíbrio nutricional e, possivelmente, menor custo. Ressalta-se, no entanto, que diversos fatores devem ser levados em consideração na prescrição das dietas caseiras, como por exemplos a composição nutricional, instrução ao proprietário de forma clara e objetiva com percepção de sua capacidade de compreender e acatar o recomendado quanto ao emprego e preparo da dieta e possibilidade de modificações nas fórmulas pelo tutor (Remillard 2008).

Alguns estudos têm demonstrado o elevado número de receitas de dietas caseiras, não convencionais, disponibilizadas em livros e "websites" e sua adequação nutricional, bem como a adesão dos proprietários a este tipo de alimento (Lauten et al. 2005, Laflamme et al. 2008, Felix et al. 2009, Jeremias et al. 2009, Saad \& França 2010, Larsen et al. 2012, Stockman et al. 2013, Oliveira et al. 2014, Johnson et al. 2016). 0 estudo realizado por Oliveira et al. (2014) agregou informações de tutores de cães sobre a percepção no uso de dietas caseiras na cidade de Jaboticabal, interior do Estado de São Paulo, a qual é composta por aproximadamente 75 mil habitantes, semelhante ao presente trabalho. Segundo Aptekmann et al. (2013) fatores culturais relacionados ao ambiente podem interferir de forma significativa sobre o comportamento humano e estes podem influenciar nas decisões relacionadas ao manejo nutricional dos animais de estimação. Desta forma, este estudo objetivou avaliar a adesão às dietas caseiras de proprietários de cães residentes na cidade de São Paulo/Brasil, bem como a percepção dos mesmos em relação aos benefícios deste tipo de alimento.

\section{MATERIAL E MÉTODOS}

O modelo de investigação utilizado foi o de pesquisa de campo do tipo descritiva mediante aplicação de questionário. 0 estudo foi aprovado pela comissão de ética no uso de animais (protocolo no 8100250615). Foram selecionados 110 proprietários de cães alimentados com dieta caseira, que a empregaram por no mínimo seis meses, prescrita pela Equipe de nutrologia canina e felina, junto ao Serviço de Clínica Médica de Pequenos Animais do Hospital Veterinário da Faculdade de Medicina Veterinária e Zootecnia da Universidade de São Paulo (FMVZ/USP), no período de julho de 2012 a agosto de 2013, sendo todos os tutores residentes na cidade de São Paulo/SP, Brasil. Do total, apenas 55 tutores apresentaram disponibilidade em responder o questionário e seus respectivos animais foram incluídos no estudo.

Durante o atendimento clínico estes também receberam avaliação nutricional que consistiu em anamnese e histórico alimentar, peso corporal, determinação do escore de condição corporal e índice de massa muscular, segundo a classificação de Laflamme (1997) e Michel et al. (2009), respectivamente. Todos os animais receberam a prescrição de dieta caseira completa e balanceada, formulada para atender as necessidades específicas de acordo com cada afecção clínica, através do software Super Crac (TD Sof- tware, Viçosa/MG, Brasil). Os ingredientes empregados nas dietas foram: arroz, carne bovina ou frango, fígado bovino, cenoura, vagem, sal, óleo de soja, fosfato bicálcico, levedura de cerveja e suplemento mineral e vitamínico. Para o cálculo da quantidade de alimento foi considerado o peso corporal de cada paciente, seguindo as recomendações do National Research Council (2006). As instruções de preparo consistiram em pesagem conforme quantidades prescritas, cozimento e conservação em geladeira ou freezer. A suplementação vitamínico-mineral foi realizada no momento do fornecimento da dieta aos animais para que não houvesse perda nutricional por aquecimento. 0 questionário utilizado no estudo, constituído de 22 perguntas, foi adaptado ao desenvolvido e publicado por Oliveira et al. (2014), conforme apresentado no quadro 1, o qual foi aplicado através de contatos telefônicos, com tempo médio de pesquisa de 20 a 30 minutos. Os dois entrevistadores passaram por treinamento prévio para que as perguntas e respostas fossem explanadas sempre da mesma forma, para que não houvesse interferência do entrevistador nos resultados da pesquisa. Os proprietários eram convidados a responder as questões pela leitura, por parte do entrevistador, de todas as opções de resposta e, a seguir, estes indicavam a que melhor se enquadrava em sua opinião. 0 questionário foi constituído de perguntas relacionadas às dificuldades no preparo da dieta, a adesão do proprietário à prescrição, avaliação subjetiva da qualidade das fezes e pelagem e percepção dos proprietários quanto à aceitação da dieta pelos cães e sua efetividade, sendo esta considerada efetiva quando a queixa do tutor foi atendida com a instituição da dieta caseira.

A análise dos resultados foi realizada por estatística descritiva e as frequências das respostas expressas em porcentagem. Além disso, para avaliações dos fatores relacionados às alterações nas fórmulas das dietas por parte dos proprietários, sem prévia avaliação pela equipe de nutrologia, as respostas foram analisadas no programa Statistical Package for the Social Sciences - SPSS 17 (SPSS Inc.). As variáveis dicotômicas foram codificadas de forma a atribuir o valor um (1) à resposta que pudesse estar associada à mudança da fórmula prescrita como um fator de risco e os valores crescentes de risco e zero (0), o contrário. 0 nível de associação de cada variável com a variável dependente (mudança da fórmula prescrita) foi avaliado pelo teste de qui-quadrado ou teste de Fischer. As variáveis mais associadas à variável dependente $(p<0,20)$ foram submetidas à análise múltipla, utilizando-se o método de regressão logística stepwise forward. Foi considerado como evento de sucesso para as variáveis dicotômicas o valor um (1) e para as variáveis qualitativas categóricas as classes foram comparadas entre si com relação à de menor risco. Variáveis que causassem alteração superior a $10 \%$ do odds ratio das anteriormente incluídas no modelo múltiplo foram desconsideradas $(\mathrm{p}<0,05)$.

\section{RESULTADOS}

Com relação ao perfil dos cães que participaram da pesquisa (Fig.1), observou-se que apenas $21,9 \%$ dos cães que receberam prescrição de dieta caseira eram hígidos, enquanto que os demais apresentavam afecções, dentre elas: neoplasias $(18,3 \%)$, alterações no sistema tegumentar $(14,5 \%)$, afecções gastrintestinais $(12,7 \%)$, urinário $(7,2 \%)$, cardiovascular $(3,6 \%)$, locomotor $(1,8 \%)$, endocrinopatias $(1,8 \%)$ e afecções multissistêmicas (18,3\%). Observou-se que $45,9 \%$ dos animais, tanto hígidos como enfermos, não aceitavam dieta comercial, sendo esta a principal motivação para a prescrição da mesma. Já $27 \%$ dos proprietários buscavam orientação nutricional para utilizar dieta caseira, por acreditarem que esta é mais saudável que a comercial, 
$13,5 \%$ já recebiam dieta caseira e almejavam o adequado balanceamento da dieta e do manejo nutricional e os 13,6\% restantes tinham outras motivações não destacadas.

Verificou-se que a maioria $(83,6 \%)$ dos proprietários eram os responsáveis pela preparação da dieta, enquanto que
$16,4 \%$ delegavam a tarefa a empregados ou membros da família. Em relação ao preparo da dieta, apenas 10,9\% citaram alguma dificuldade, sendo que destes $33,3 \%$ evidenciaram o tempo dispendido e $16,6 \%$ o método de pesagem dos ingredientes como fatores que dificultaram o preparo.

\section{Quadro 1. Questionário aplicado aos tutores dos cães alimentados com dieta caseira inclusos no estudo}

1. Quem prepara a dieta?

A. Você

B. Empregada

C. Outra pessoa

D. Outra opção

2. Quando recebeu a dieta pela equipe da nutrição do HOVET/USP, você (ou a pessoa que prepara) achou a dieta...

A. Fácil de fazer

B. Não se preocupou com isto

C. Difícil de fazer

D. Outra opção:

2.b. Caso tenha havido dificuldade, qual a principal dificuldade no preparo da dieta:

A. Trabalho para preparar

B. Tempo de preparo

C. Dificuldade em pesar os ingredientes

D. Outra opção:

3. Fez alguma modificação na dieta?

A. Sim

B. Não

3.b. Qual?

A. Trocaram a carne

B. Acrescentaram mais carne

C. Acrescentou outro alimento

D. Variou os legumes

E. Retirou o fígado cozido

F. Retirou a cenoura cozida

G. Temperou com cebola e alho

H. Outra opção:

4. No preparo da dieta

A. cozinho todos os alimentos

B. cozinho só alguns alimentos

4.b. Caso forneça algum alimento cru, identifica-

-lo(s) abaixo:

5. Como você define quanto fornecer de cada coisa

A. Tem balança em casa

B. Mede por volume com equipamento que tem em casa

C. Usa o guia de colheradas que foi fornecido na receita pela equipe de nutrição

D. Tem noção das quantidades e define na hora, por você mesma (a)

6. Como você define quanto colocar de carne?

A. Coloco exatamente a quantidade estabelecida na receita

B. Coloco mais ou menos a quantidade estabelecida

C. Evito faltar, assim tendo a colocar bastante

D. Evito colocar em excesso, assim restrinjo

quanto fornecer

E. Outra opção:

7. Como você define quanto colocar de arroz?

A. Coloco exatamente a quantidade estabelecid na receita

B. Colo lecida

C. Evito faltar, assim tendo a colocar bastante

D. Evito colocar em excesso, assim restrinjo

quanto fornecer

E. Outra opção:
8. Como você define quanto colocar de legumes? 14. Como você define a quantidade total de

A. Coloco exatamente a quantidade estabelecida alimento que fornece? na receita

B. Coloco mais ou menos a quantidade estabelecida

C. Evito faltar, assim tendo a colocar bastante

D. Evito colocar em excesso, assim restrinjo

quanto fornecer

E. Não coloco

F. Outra opção:

9. Como você define quanto colocar de sal?

A. Dou exatamente o que esta na receita

B. Acho pouco, dou um pouco mais

C. Acho muito, dou um pouco menos

D. Dou mais ou menos o que está na receita

15. Caso sobre alimento, o que faz quando com a sobra no pote?

A. Acho normal, não tomo atitude

B. Passo a fornecer menos comida

C. Mudo a receita, colocando mais o que ele

A. Coloco exatamente a quantidade estabelecida gosta para estimular o consumo

na receita

B. Coloco mais ou menos a quantidade estabelecida

C. Evito faltar, assim tendo a colocar bastante

D. Evito colocar em excesso, assim restrinjo

quanto fornecer

E. Não coloco

F. Outra opção:

10. Como você define quanto colocar de óleo?

A. Coloco exatamente a quantidade estabelecida na receita

B. Coloco mais ou menos a quantidade estabelecida

C. Evito faltar, assim tendo a colocar bastante

D. Evito colocar em excesso, assim restrinjo quanto fornecer

E. Utilizo outro tipo de óleo

F. Não coloco

G. Outra opção:

11. Como você define quanto colocar de suple-

D. Não sobra alimento

E. Outra opção:

16. Em relação ao custo da dieta caseira..

A. Não é tão importante, faço por achar

melhor/o cão gosta mais

B. Mais barata que ração

C. Mais cara que ração

D. Achou caro fazer a dieta?

E. Não percebeu diferença de custo ou não sabe

F. Outra opção:

17. As fezes do cão são...

A. Boas

B. Um pouco moles

C. Muito moles

D. Ressecadas

E. Outra opção:

18. Em comparação a quando ele comia ração, as fezes são...

A. Iguais a quando comia ração

B. Pior que quando comia ração

mento vitamínico-mineral (aminomix, levedura de C. Nunca comeu/aceitou ração, sempre comeu

cerveja, carbonato de cálcio ou fosfato bicálcico)? dieta caseira

A. Coloco exatamente a quantidade estabelecida D. Outra opção:

19. Notou alteração de pelagem após o fornecimento da dieta caseira?

B. Coloco mais ou menos a quantidade estabelecida

C. Evito faltar, assim tendo a colocar bastante

D. Evito colocar em excesso, assim restrinjo quanto fornecer

E. Não coloco

F. Outra opção:

12. Quem alimenta o cão, acha que ele....

A. Gosta muito da comida

B. Come a comida, mas não gosta muito

C. Não gosta da comida

D. Outra opção:

13. Dos itens fornecidos....

A. Ele come tudo

B. Ele não gosta de algum e o rejeita

C. Ele não gosta de algum, mas acaba comendo pois está misturado

A. Não, esta igual

B. Esta pior

C. Esta melhor

D. Outra opção:

20 - Você acha que a dieta caseira foi....

A. Efetiva

B. Não foi efetiva

C. Não fez diferença (já comia dieta caseira)

21 - Motivo da prescrição da dieta caseira:

A. Prefiro dieta caseira à ração, acredito que seja mais saudável

B. Não estava mais comendo ração

C. Sempre comeu dieta caseira, e só procurei o serviço para balanceá-la

D. Outra opção:

22 - Seu animal foi

D. Outra opção:

13.b. Caso haja, Qual/quais os itens que ele não

gosta:

A. Legumes

B. Suplementação vitamínico-mineral

C. Fígado cozido

D. Outra opção: diagnosticado com alguma

doença? Por favor, escrever abaixo:

Pesq. Vet. Bras. 37(12):1453-1459, dezembro 2017 
Em relação ao método de pesagem, $63,6 \%$ utilizaram a balança e/ou o guia de colheradas, os quais foram recomendados pela equipe de nutrologia, enquanto que $36,4 \%$ relataram definição da quantidade no momento e/ou através da relação de volume médio dos ingredientes.

Quando questionados sobre modificações nas dietas, verificou-se que $60 \%$ dos proprietários realizaram algum tipo de mudança sem prévia comunicação com o profissional. Destes, 25\% modificaram o tipo de carne, 37,5\% incluíram outro ingrediente não prescrito, $40,6 \%$ variaram os legumes e $12,5 \%$ temperaram com cebola e alho. Alguns deles realizaram mais de um tipo de alteração. Com relação à definição das quantidades de cada ingrediente, dentre os proprietários que realizaram modificações, foi verificado que número maior de tutores incluía de forma aleatória a quantidade de carne, arroz e legumes, do que a inclusão exata da quantidade destes ingredientes prescritos. Em relação ao sal e óleo, houve elevada frequência de tutores que incluíram quantidade abaixo do prescrito e para a suplementação vitamínico-mineral observou-se que um terço dos entrevistados não a realizaram (Figura 2). Ainda em relação ao processo de produção das dietas, os tutores foram questionados quanto à indicação do cozimento dos ingredientes pela equipe de nutrologia e observou-se que $85,45 \%$ seguiram a recomendação e cozeram todos os ingredientes, enquanto que $14,55 \%$ não seguiram o recomendado.

No manejo alimentar dos animais observou-se que a maioria dos proprietários forneceram a quantidade recomendada $(51,8 \%)$, já $35,1 \%$ não apresentavam controle exato; $9,3 \%$ acreditavam ser pouco alimento e 3,8\% restringiram a quantidade por julgarem excessiva. A maioria dos proprietários relatou não haver sobra de alimento $(52,7 \%)$, informação confirmada pelo elevado percentual de animais que gostaram muito da dieta $(74,5 \%)$, no entanto, quando havia sobra do alimento, alguns dos entrevistados não tomaram nenhuma atitude $(36,3 \%)$, poucos entrevistados mudaram a apresentação do alimento na tentativa de estimular o consumo $(7,2 \%)$ e a minoria forneceu menos alimento $(3,6 \%)$.
Observou-se que $37,2 \%$ dos animais passaram a rejeitar o alimento quando adicionado o suplemento vitamínico-mineral; 9,8\% rejeitaram os legumes; 3,9\% rejeitaram o fígado e $57,4 \%$ não apresentaram qualquer tipo de rejeição. Alguns deles, passaram a rejeitar o alimento com a inclusão de mais de um destes ingredientes. Na Figura 3 estão apresentadas as principais atitudes dos tutores frente às rejeições destes ingredientes pelos animais. Dos casos (42.5\%) que apresentaram algum tipo de rejeição, $60 \%$ delas foram devido ao suplemento, $10 \%$ não aceitaram os legumes, $10 \%$ rejeitaram os legumes e suplemento, $5 \%$ recusaram o fígado, e $5 \%$ fígado e suplemento.

Ao avaliar os principais pontos benéficos da dieta caseira em comparação à comercial, a metade dos proprietários $(50,00 \%)$ não relataram melhora das fezes e parcela ainda maior $(66,79 \%)$, não relataram diferença na pelagem dos animais (Figura 4). No entanto, elevado percentual (79\%) citaram efetividade da dieta caseira em relação ao objetivo de sua prescrição. Em relação aos tutores que observaram diferença nas fezes e pelagem em comparação à dieta comercial antes consumida pelos cães, $34 \%$ relataram melhora nas fezes e $32,5 \%$ na pelagem. Apenas uma minoria $(15,9 \%)$ re-

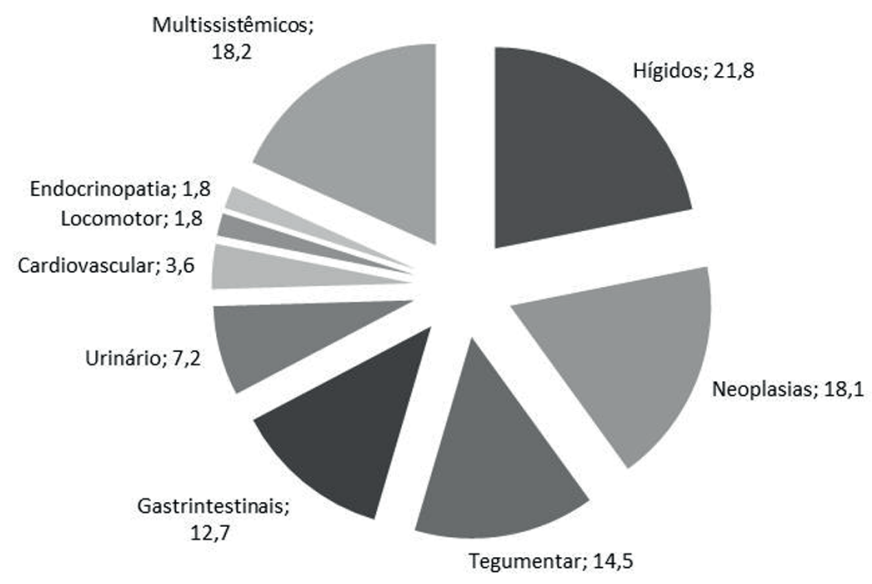

Fig.1. Perfil dos cães participantes da pesquisa.

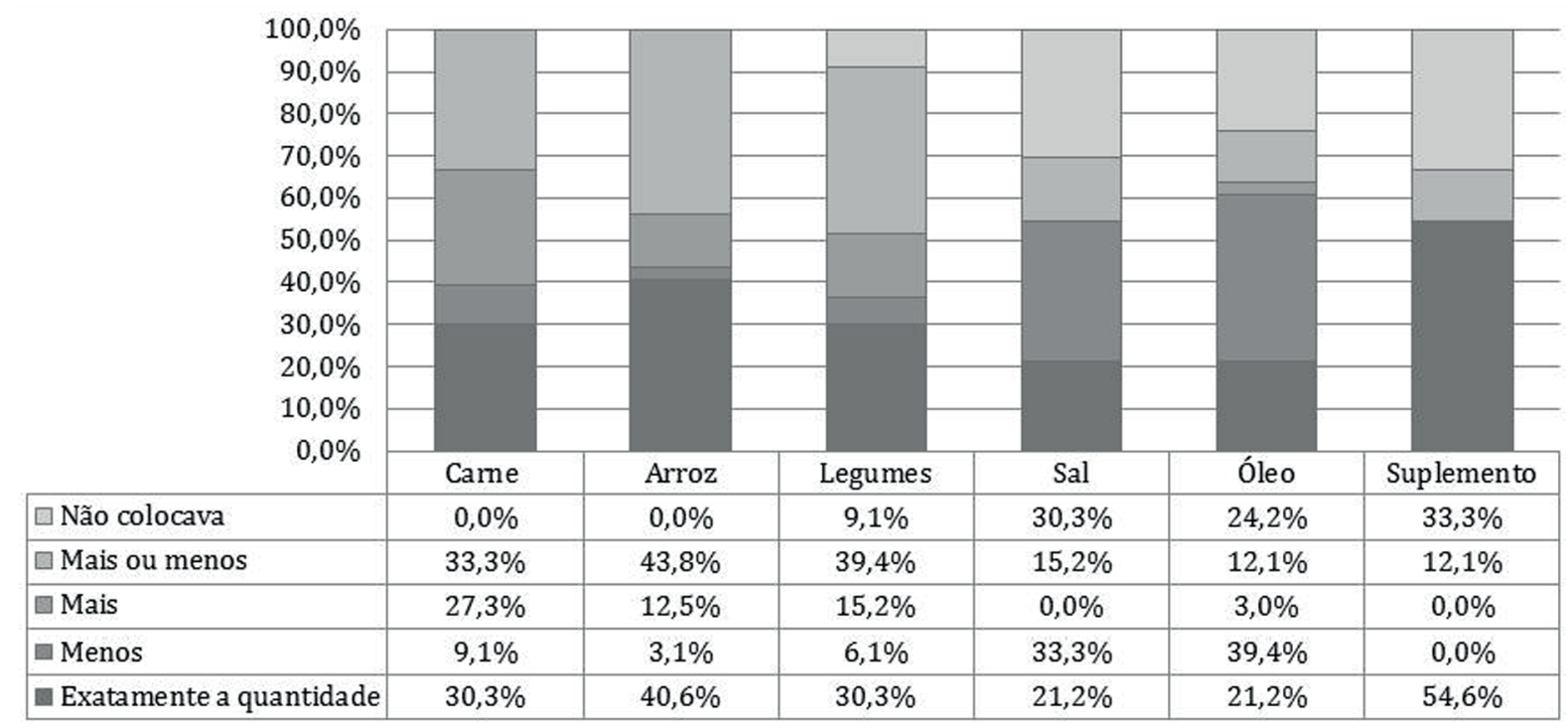

Fig.2. Quantidade dos ingredientes definida pelos tutores no preparo das dietas caseiras. 
feriu piora das fezes e pelagem (4,65\%). Em relação ao custo da dieta caseira (Fig.5); 40,91\% não consideraram o valor como uma questão importante; $27,27 \%$ consideraram mais barata que a comercial; 6,82\% mais cara que a comercial e 25,0\% dos entrevistados relataram não saber.

Com relação à análise das alterações nas fórmulas das dietas por parte dos proprietários, pode-se verificar no quadro 2 que a dificuldade no preparo da dieta, custo e palatabilidade $(p<0,20)$ foram fatores que estiveram associados a variável dependente (mudança da fórmula prescrita). No entanto, na avaliação através do modelo múltiplo de regressão logística pode-se inferir que proprietários que acreditaram que a dieta caseira era mais cara que a comercial apresentaram cinco vezes mais chance de alterar a fórmula prescrita do que proprietários que discordavam de tal afirmação.

\section{DISCUSSÃO}

O perfil dos tutores e cães avaliados no presente estudo não foi padronizado, sendo considerados animais de diferentes faixas etárias, raças e afecções clínicas. No entanto, como trata-se de um levantamento exploratório da percepção dos proprietários e manejo nutricional dos animais mediante o uso de dieta caseira, tal padronização não é imprescindível.

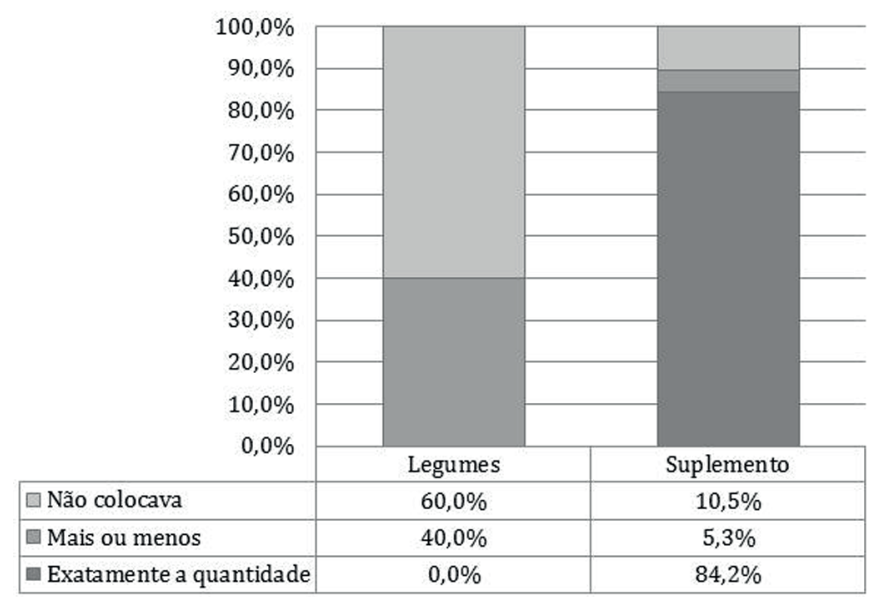

Fig.3. Relação entre a rejeição de determinado ingrediente pelos animais e a atitude dos tutores no preparo da dieta.
Pode-se verificar que, de forma geral, a busca pela dieta caseira esteve associada ao fato do cão não ingerir o alimento comercial e este fator parece estar relacionado à elevada frequência de animais com afecções clínicas incluídos na pesquisa. No estudo publicado por Oliveira et al. (2014) os autores observaram que 93,5\% dos proprietários utilizaram a dieta caseira para manejar uma doença específica ou devido a hiporexia. Animais doentes, na maioria das vezes, apresentam-se em estado de hiporexia (Brunetto et al. 2010), nestes casos, a dieta caseira é uma alternativa efetiva para colocar os pacientes em balanço energético positivo, uma vez que no geral apresentam melhor aceitação pelos animais.

Parcela expressiva dos tutores (27\%) buscaram a dieta caseira como forma de alimentação mais saudável, sendo observado na literatura que de forma geral tal escolha está associada ao fato de reforçar a ligação com o animal ao preparar o alimento, opção por ingredientes frescos e também para evitar aditivos e contaminantes. Somado aos aspectos anteriores, outros motivos incluem o desconhecimento dos ingredientes descritos no rótulo e a percepção do uso de substâncias potencialmente perigosas, palatabilidade, personalização da dieta, preferência por determinado ingrediente, afecções clínicas, restrição de substância alergênica, crença que animais necessitam de variação nos ingredientes da dieta e o desejo de alimentar o animal de acordo com recomendações nutricionais para seres humanos (Michel 2006, Remillard 2008, Remillard \& Crane 2010, Johnson et al. 2016).

De forma geral, os proprietários não citaram dificuldade no preparo do alimento, contudo a interpretação deste fato requer cautela, uma vez que foram entrevistados apenas proprietários que previamente aceitaram empregar dieta caseira. Dentre os que relataram dificuldade, o tempo de preparo pareceu ser o fator mais citado. Ressalta-se que foi recomendado o cozimento de todos os ingredientes para evitar a contaminação microbiana, sendo que a grande maioria dos proprietários manteve o preconizado. Os proprietários que não cozinharam todos os ingredientes não foram questionados em relação aos alimentos fornecidos crus e suas motivações, sendo importante tal avaliação em futuras pesquisas, já que as carnes podem apresentar

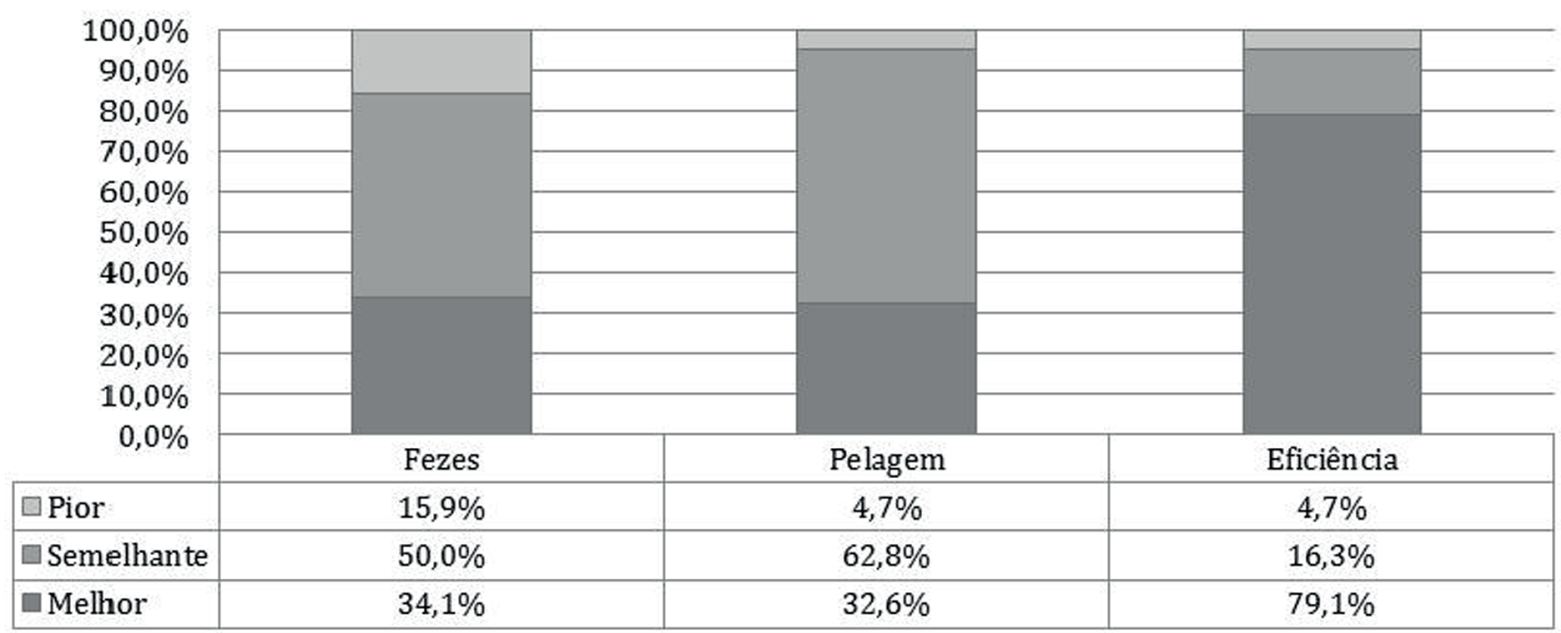

Fig.4. Percepção dos proprietários em relação às fezes, pelagem e eficiência das dietas caseiras em comparação as dietas comerciais. 


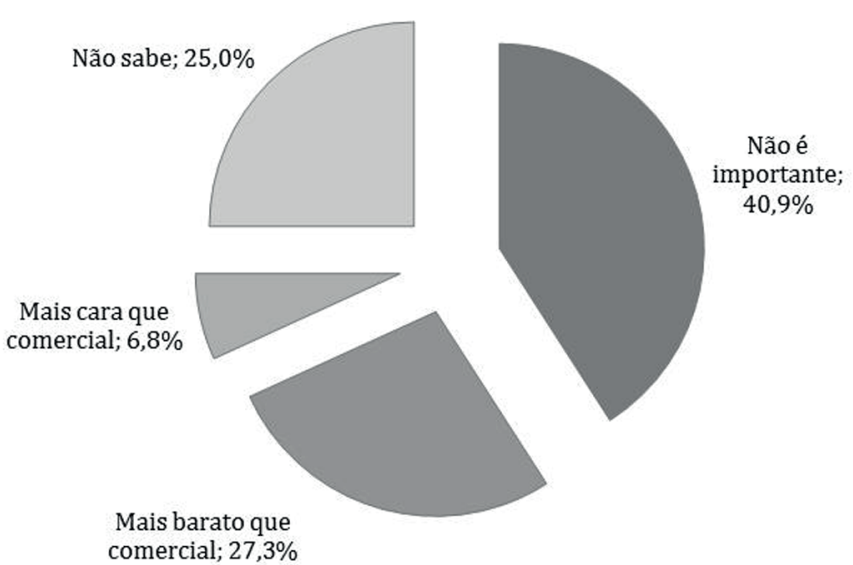

Fig.5. Comparativo de custo das dietas caseiras e comerciais pelos tutores.

Quadro 2. Análise univariada para avaliação da associação das variáveis à mudança na dieta e modelo múltiplo de regressão logística

\begin{tabular}{|c|c|c|}
\hline \multicolumn{3}{|c|}{ Análise univariada } \\
\hline \multicolumn{2}{|l|}{ Variáveis } & $\mathrm{P}^{*}$ \\
\hline \multicolumn{2}{|l|}{ Dificuldade no preparo $^{a}$} & 0,126 \\
\hline \multicolumn{3}{|l|}{ Custo ${ }^{b}$} \\
\hline \multicolumn{3}{|l|}{$\begin{array}{l}\text { Não é importante, faço por } \\
\text { achar melhor/o cão gosta mais }\end{array}$} \\
\hline \multicolumn{3}{|l|}{ Mais barata que ração comercial } \\
\hline \multicolumn{3}{|l|}{ Mais cara que ração comercial } \\
\hline Não sabe/não percebeu a dife & ença & 0,149 \\
\hline \multicolumn{3}{|c|}{ Palatabilidade da dieta ${ }^{\mathrm{b}}$} \\
\hline \multicolumn{3}{|l|}{ Gosta muito } \\
\hline \multicolumn{3}{|l|}{ Come, mas não gosta muito } \\
\hline Não gosta & & 0,177 \\
\hline \multicolumn{3}{|c|}{ Modelo múltiplo } \\
\hline Variável & Odds ratio (IC 95\%) & $\mathrm{P}^{* *}$ \\
\hline Mais cara que ração comercial & $6,002(1,135-31,747)$ & 0,035 \\
\hline
\end{tabular}

riscos para a saúde dos animais e a transmissão de zoonoses (Weese et al. 2005, Michel 2006, American Veterinary Medical Association 2013, Canadian Veterinary Medical Association 2013, Weeth 2013).

Apesar dos tutores não se importarem com as desvantagens relacionadas ao tempo de preparo, armazenamento e fornecimento da dieta caseira, os mesmos parecem não compreender as consequências dos desbalanços nutricionais sobre a saúde dos animais, já que foi observada elevada porcentagem de proprietários que alteraram a fórmula prescrita sem prévia avaliação pelos nutrólogos, de forma semelhante aos achados de Oliveira et al. (2014) que também observaram elevada frequência de alterações nas fórmulas.

Relevantes alterações parecem estar relacionadas às indicações da nutrição humana, tais como redução de óleo e sal, ou seja, os tutores tendem a extrapolar os mesmos conceitos para cães e gatos, sem compreensão das diferenças interespécies, já que estes animais são bastante tolerantes a gordura na dieta, com metabolismo lipídico diferente de seres humanos e não apresentam hipertensão associada à elevada ingestão do cloreto de sódio (Terpstra et al. 1982, Whitney 1992, Bauer 2004, Chandler 2008, Remillard 2008). Este é um ponto bastante importante de ser considerado na prescrição das dietas, sendo fundamental explicar e conscientizar os tutores sobre o papel dos ingredientes e a problemática da alteração de sua concentração sem prévia avaliação por um profissional da área. 0 fornecimento de uma lista com alimentos que podem ser substituídos e seus substitutos seria importante para evitar o desbalanceamento das dietas, bem como a avaliação periódica das fórmulas e dos animais (Michel 2006, Remillard 2008, Remillard \& Crane 2010, Weeth 2013).

Pôde-se verificar ainda que um terço dos proprietários não incluíram na dieta o suplemento vitamínico mineral, percentual semelhante ao observado por Oliveira et al. (2014), sendo que este fato não parece estar associado a rejeição do ingrediente pelo animal, já que apenas pouco mais de $10 \%$ dos proprietários dos cães que rejeitavam o suplemento não o incluíam. Desta forma, possíveis explicações para a exclusão do suplemento vitamínico mineral da dieta podem estar relacionadas ao custo do produto ou ao desconhecimento das necessidades pelo animal. Além disso, a recomendação da inclusão do suplemento somente após o processo de produção da dieta, talvez possa ter contribuído para que os proprietários negligenciassem sua inclusão (Remillard 2008) e também pela preferência própria da não inclusão de aditivos. Neste sentido, é importante ressaltar os achados de Kawaguchi et al. (1993) e Sturion \& Pereira (1995) que demonstraram desenvolvimento de hiperparatireoidismo secundário nutricional em cães alimentados com dietas caseiras inadequadas em vitaminas e minerais. No entanto, como limitação no presente estudo, os proprietários não foram questionados quanto ao motivo da exclusão da suplementação vitamínico-mineral.

Em relação ao método de pesagem das matérias primas, observou-se que um terço dos proprietários definiu a quantidade no momento do preparo e/ou pela relação volume médio dos ingredientes de forma empírica. É importante ressaltar que este fato pode gerar desbalanços nutricionais na formulação da dieta, já que a percepção do proprietário pode não ser fidedigna. Esse aspecto demonstra a importância de se explicitar de forma clara as porções dos ingredientes a serem utilizadas na dieta, como nas fontes cárneas, por exemplo, que sofrem importante alteração na relação de proteína e gordura de acordo com as espécies e os cortes (Michel 2006). Flutuações nos componentes podem descompensar animais com determinadas afecções clínicas (Weeth 2013). Além disso, é importante ressaltar que pouco menos da metade dos proprietários não controlavam a quantidade de alimento a ser fornecido aos animais, antes de serem orientados pela equipe de nutrologia.

Observou-se ainda que pequena parcela $(13,5 \%)$ dos proprietários buscavam o adequado balanceamento da dieta, muito semelhante ao encontrado por Johnson et al. (2016). Estes autores concluíram que apenas 13\% dos proprietários seguiram estritamente as recomendações de quantidade das dietas caseiras prescritas pelo Serviço de Nutrição. Este fato é bastante importante ao considerar o 
elevado número de receitas de dietas caseiras disponibilizadas em livros e websites. Estes meios de informação são importantes para muitos proprietários, conforme relatado por Aptekmann et al. (2013) que observaram que $41 \%$ utilizavam lojas agropecuárias e pet shops como fonte de informação, $32 \%$ os estudantes de medicina veterinária e profissionais formados, $30 \%$ os websites e $16 \%$ as revistas. Laflamme et al. (2008) observaram em estudo conduzido nos EUA e Austrália que pouco menos de um terço dos proprietários que empregavam dietas caseiras utilizavam dietas com formulação específica para seus animais. Sugere-se uma futura avaliação da frequência de proprietários que utilizam estas ferramentas como fonte de informação e fornecem aos animais sem prévia avaliação por profissionais da área, já que tais dietas podem conter importantes desbalanços nutricionais (Lauten et al. 2005, Larsen et al. 2012, Stockman et al. 2013).

Com relação à efetividade da dieta caseira em relação aos anseios dos proprietários, verificou-se que a maioria mostrou-se satisfeitos, seja pela busca por alimento "natural" ou na evolução clínica de animais com afecções. 0 custo não pareceu ser um fator relevante para os proprietários. No entanto, este ponto deve ser avaliado com critério, pois para redução de custos, possíveis alterações nas fórmulas podem ter sido realizadas. Ressalta-se que um dos entraves em relação ao custo pode ser o fato dos proprietários não apresentarem conhecimento na comparação dos custos da dieta caseira e comercial em base de matéria seca, e acreditam que o custo da dieta caseira é reduzido. Além disso, como a aquisição dos ingredientes é consorciada com alimentos de consumo das pessoas, as finanças se confundem, ou seja, a utilização de fonte de energia para a preparação dos alimentos e o tempo muitas vezes não são contabilizados, com isso o custo não é adequadamente avaliado. Especula-se ainda que possíveis oscilações monetárias e no custo de determinadas matérias primas podem repercutir em alterações das formulações.

\section{CONCLUSÕES}

As dietas caseiras apresentam-se como importante ferramenta nutricional no manejo alimentar de cães, com avaliação positiva dos proprietários em relação a sua efetividade, os quais são os principais responsáveis pela sua confecção.

No entanto, nem todos estão aptos a empregá-la de forma adequada e segura.

\section{REFERÊNCIAS}

Aptekmann K.P., Mendes-Junior A.F., Suhett W.G. \& Guberman U.C. 2013. Manejo nutricional de cães e gatos domiciliados no estado do Espírito Santo - Brasil. Arq. Bras. Med. Vet. Zootec. 65(2):455-459.

American Veterinary Medical Association 2013. Disponível em <www. avma.org/kb/policies/pages/raw-or-undercooked-animal-source-protein-in-cat-and-dog-diets.aspx> Acesso em 26 ago. 2014.

Bauer J.E. 2004. Lipoprotein-mediated transport of dietary and synthesized lipids and lipid abnormalities of dogs and cats. J. Am. Vet. Med. Assoc. 224(5):668-675.

Brunetto M.A., Gomes M.O.S., Andre M.R., Teshima E., Gonçalves K.N., Pereira G.T., Ferraudo A.S. \& Carciofi A.C. 2010. Effects of nutritional support on hospital outcome in dogs and cats. J. Vet. Emerg. Crit. Care 20(2):224-231.
Canadian Veterinary Medical Association 2013. Disponível em <http:// cvma.net/resources/cvma-policies/animals-general-policies/cvma-policy-on-raw-or-undercooked-animal-source-protein-in-cat-and-dog-diets/> Acesso em 3 mar. 2014.

Chandler M.L. 2008. Petfood safety: sodium in pet foods. Top. Compan. Anim. Med. 23(3):148-153.

Félix A.P., Sá-fortes C.M.L., Silva A.C.M., Nascimento S.T., Carciofi A.C., Laurentiz A.C. \& Bergamaschine A.F. 2009. Digestibilidade de uma dieta caseira e dois alimentos comerciais, econômico e super-prêmio, para cães. Arch. Vet. Sci. 14(1):25-30.

Jeremias J.T., Carciofi A.C., Brunetto M.A., Nogueira S.P., Gomes M.O.S. \& Teshima E. 2009. Manejo nutricional e digestibilidade no quilotórax canino. Ciência Rural 39(1):258-261.

Johnson L.N., Linder D.E., Heinze C.R., Kehs R.L. \& Freeman L.M. 2016. Evaluation of owner experiences and adherence to home-cooked diet recipes for dogs. J. Small Anim. Pract. 57:23-27.

Kawaguchi K., Braga I.S., Takahashi A., Ochiai K. \& Itakura C. 1993. Nutritional secondary hyperparathyroidism occurring in a strain of german shepherd puppies. J. Vet. Res. 41(2/4):89-96.

Laflamme D.P. 1997. Development and validation of a body condition score system for dogs. Canine Pract. 22(4):10-15.

Laflamme D.P., Abood S.K., Fascetti A.J., Fleeman L.M., Freeman L.M., Michel K.E., Bauer C., Kemp B.L., Doren J.R. \& Willoughby K.N. 2008. Pet feeding practices of dog and cat owners in the United States and Australia. J. Am. Vet. Med. Assoc. 232(5):687-694.

Larsen J.A., Parks E.M., Heinze C.R. \& Fascetti A.J. 2012. Evaluation of recipes for home-prepared diets for dogs and cats with chronic kidney disease. J. Am. Vet. Med. Assoc. 240(5):532-538.

Lauten S.D., Smith T.M. \& Kirkd C.A. 2005. Computer analysis of nutrient sufficiency of published home-cooked diets for dogs and cats. J. Vet. Intern. Med. 19:23-28.

Michel K.E. 2006. Unconventional diets for dogs and cats. Vet. Clin. North Am. Small Anim. Pract. 36(6):1269-1281.

Michel K.E., Anderson W. \& Cupp C. 2009. Validation of a subjective muscle mass scoring system for cats. J. Anim. Physiol. Anim. Nutr. 793:806. (Abstract)

National Research Council 2006. - Nutrient requirements of dogs and cats. National Academy of Science, National Academy Press, Washington, D.C.

Oliveira M.C.C., Brunetto M.A., Silva F.L., Jeremias J.T., Tortola L., Gomes M.O.S. \& Carciofi A.C. 2014. Evaluation of the owner's perception in the use of homemade diets for the nutritional management of dogs. J. Nutr. Sci. 3(e23):1-5.

Remillard R.L. 2008. Homemade diets: Attributes, pitfalls, and a call for action. Top. Compan. Anim. Med. 23(3):137-142.

Remillard R.L. \& Crane S.W. 2010. Making pet foods at home, p.207-223. In: Hand M.S., Thatcher C.D., Remillard R.L. \& Roudebusch P. (Eds), Small Animal Clinical Nutrition. 5th ed. Mark Morris Institute, Topeka.

Saad F.M.O.B. \& França J. 2010. Alimentação natural de cães. Revta Bras. Zootec. 39(Supl.Esp.):52-59.

Sturion D.J. \& Pereira P.M. 1995. Diagnóstico radiográfico de caninos e felinos com hiperparatireoidismo nutricional secundário. Semina, Ciênc. Agrárias 16(1):28-33.

Stockman J., Fascetti A.J., Kass P.H. \& Larssen J.A. 2013. Evaluation of recipes of home-prepared maintenance diets for dogs. J. Am. Vet. Med. Assoc. 242(11):1500-1505.

Terpstra A.H.M., Sanchez-Muniz F.J., West C.E. \& Woodward C.J.H. 1982. The density profile and cholesterol concentration of serum lipoproteins in domestic and laboratory animals. Comp. Biochem. Phys. 71(4):669763.

Weese J.S., Rousseau J. \& Arroyo L. 2005. Bacteriological evaluation of commercial canine and feline raw diets. Can. Vet. J. 46(6):513-516.

Weeth L.P. 2013. Focus on nutrition: home-prepared diets for dogs and cats. Compend. Contin. Educ. Vet. 35(3):E1-E3.

Whitney M.S. 1992. Evaluation of hyperlipidemias in dogs and cats. Semin. Vet. Med. Surg., Small Anim. 7(4):292-300. 